\title{
APLICAÇÃO DO CRAM DOWN NO ORDENAMENTO JURÍDICO BRASILEIRO
}

\author{
Cristiane Akemi Perigolo Tsujiguchi; João Paulo Angelo Vasconcelos \\ Universidade do Oeste Paulista - UNOESTE, Curso de Direito Presidente Prudente, SP.
}

\section{RESUMO}

O presente artigo teve como objetivo demonstrar o poder do juiz e os requisitos de aplicação do instituto do cram down, originariamente norte-americano e adaptado ao direito brasileiro. $\mathrm{O}$ tema foi introduzido com a possibilidade de uma empresa enfrentar uma crise e se utilizar do processo de recuperação judicial para retomar o exercício regular da atividade econômica explorada. A partir do processo de recuperação judicial, foi abordado o instituto do cram down, que pode ser encontrado na fase deliberativa do referido processo e que tem sido objeto de discussões doutrinárias e de formação de jurisprudências acerca do tema no Brasil. Foram apresentadas as características do instituto em sua forma originária e na adaptada no ordenamento jurídico brasileiro e analisada a sua aplicação relativizada pelos princípios do direito recuperacional.

Palavras-chave: Recuperação judicial de empresas. Cram down. Direito norte-americano. Abuso de credores. Poder do juiz.

\section{APPLICATION OF CRAM DOWN IN BRAZILIAN LEGAL ORDINANCE}

\begin{abstract}
This article aims to demonstrate the power of the judge and the application requirements of the cram down institute, originally North American and adapted to Brazilian law. The theme was introduced with the possibility of a company facing a crisis and using the judicial recovery process to resume the regular exercise of the economic activity explored. From the judicial recovery process, the cram down institute was approached, which can be found in the deliberative phase of this process and which has been the subject of doctrinal discussions and the formation of jurisprudence on the subject in Brazil. The characteristics of the institute were presented in its original and adapted form in the Brazilian legal system and analyzed its application relativized by the principles of recovery law.

Keywords: Judicial recovery of companies. Cram down. North American law. Abuse of creditors. Power of the judge.
\end{abstract}




\section{INTRODUÇÃO}

A expressão empresa em crise pode ser interpretada como o momento de dificuldade em que uma sociedade empresária se encontra devido a fatores econômicos, financeiros ou patrimoniais que geram contratempos, impedindo o exercício regular e lucrativo de determinada atividade econômica.

Tendo em vista que a referida expressão está cada dia mais frequente em nosso dia-a-dia, as empresas nessa situação são obrigadas a buscar soluções para manter os postos de trabalho, o abastecimento de produtos e serviços e a contribuição para o desenvolvimento da economia local e nacional.

Uma das soluções é a recuperação judicial de empresas que se dá através da intermediação do Poder Judiciário, do auxílio do administrador judicial e das deliberações realizadas pela Assembleia Geral de Credores no desenvolvimento do processo, sempre observados a lei e os princípios do direito recuperacional.

Para tanto, é necessário que a empresa seja minimamente viável, vez que, segundo Costa (2013), empresas não prósperas devem ser retiradas do mercado, pois, assim, os recursos que se destinariam à essas empresas se direcionam a atividades produtivas, mantendo os benefícios sociais e o funcionamento regular da economia.

Dentro do processo de recuperação judicial, existe um instituto chamado cram down, que foi trazido do direito norte-americano e que pode ser aplicado na fase deliberativa do aludido processo, quando da votação do plano de recuperação apresentado pela empresa em crise, atendidos os requisitos dos $\S \S 1$ 으 e 2ㅇ do artigo 58 da Lei no 11.101 de 2005.

Neste contexto, o presente trabalho tem por objetivo estudar a complexidade dos requisitos de concessão da recuperação pelo cram down e a atuação do juiz nesta modalidade de aprovação do plano de recuperação judicial frente aos princípios do direito recuperacional.

\section{METODOLOGIA}

O presente estudo foi elaborado a partir de pesquisa bibliográfica e documental, pela indispensável leitura e interpretação de doutrinas e jurisprudências acerca do instituto do cram down, seus requisitos e sua aplicação prática.

\section{DA APLICAÇÃO DO CRAM DOWN}

O cram down é um instituto originariamente norte-americano, tendo sua regulamentação no Chapter 11 do Bankruptcy Code denominado Reorganization, mais especificamente no Subchapter II - The plan, na Section 1129(b).

Para que um plano de recuperação judicial seja aprovado, é necessário o atendimento de alguns requisitos. No direito dos Estados Unidos da América, devem ser atendidos o melhor interesse dos credores, a viabilidade econômica mínima da empresa devedora, o convencimento da solidez do plano e a aprovação por todas as classes de credores, enquanto que, no Brasil, o plano será aprovado quando obtiver, na Assembleia Geral de Credores, um quórum geral e também um específico de cada classe de credores.

Em regra, rejeitado o plano de recuperação, o juiz decretará a falência da sociedade empresária devedora. Contudo, o cram down surge como uma exceção, não limitando o magistrado à esta decretação, pois o plano não aprovado poderá ser homologado, observadas as regras do art. 58, §§ 1으 e 2 da Lei n.o 11.101 de 2005.

Nos EUA, o juiz de falências poderá impor o plano de pagamento aos credores quando presentes três requisitos: unfair discrimination, fair and equitable e feasible.

O primeiro consiste no impedimento de discriminação injusta quando do pagamento dos credores. Neste sentido, Tabb e Brubaker (2011, p. 704) entendem que: 
A proibição da injusta discriminação é projetada para proteger uma classe contra o risco de o proponente criar para outras classes do mesmo patamar legal a promoção de tratamento mais favorável no plano ${ }^{1}$.

Por sua vez, Blum (2006, p. 513) aduz que a discriminação é permitida quando não é injusta, sendo que a questão da justiça se analisa pela necessidade e motivação da discriminação, ou seja, se não é fundada na má-fé e é necessária para o sucesso da recuperação, não será injusta ${ }^{2}$.

O segundo requisito exige que o plano seja justo e equitativo, agindo, como ensina Lima Filho (2017), na esfera vertical do plano, fazendo com que a hierarquia prevaleça no pagamento das classes.

Segundo Tabb e Brubaker (2011, p. 704), este pressuposto traz a regra da absoluta prioridade (absolute priority rule), exigindo que o plano respeite a ordem das classes de credores ${ }^{3}$.

A última exigência é a da feasible que demanda que o plano seja realmente viável para a reorganização da empresa.

Nesta toada, Miller e Harrell (2002) lecionam que, além dos requisitos supracitados, "[...] o devedor deve demonstrar que o plano é economicamente viável e não provável de ser seguido por uma falência ou pela necessidade de outro processo de reorganização futuro" ${ }^{4}$.

Cabe ressaltar que o magistrado norte-americano tem auxílio técnico de um órgão chamado Securities and Exchance Comission ou SEC para constatar a viabilidade do plano.

No Brasil, o instituto foi adaptado, tendo em vista que a análise dos requisitos pelo juiz é objetiva, diferentemente da forma norte-americana que possibilita uma discricionariedade na avaliação.

As determinações do $\S 10$ do art. 58 devem ser consideradas juntamente com o $2^{\circ}$ - do mesmo dispositivo legal, tendo em vista que o quórum de deliberação alternativo só terá o condão de aprovar o plano se verificado o tratamento igualitário entre os credores das classes dissidentes.

Abaixo observam-se os requisitos constantes na Lei de Falências e Recuperações de Empresa (LFRE):

I - o voto favorável de credores que representem mais da metade do valor de todos os créditos presentes à assembleia, independentemente de classes;

II - a aprovação de 2 (duas) das classes de credores nos termos do art. 45 desta Lei ou, caso haja somente 2 (duas) classes com credores votantes, a aprovação de pelo menos 1 (uma) delas;

III - na classe que o houver rejeitado, o voto favorável de mais de $1 / 3$ (um terço) dos credores, computados na forma dos $\S \S 10$ e 20 do art. 45 desta Lei.

$\S 20$ A recuperação judicial somente poderá ser concedida com base no § 1o deste artigo se o plano não implicar tratamento diferenciado entre os credores da classe que o houver rejeitado.

\footnotetext{
${ }^{1}$ The prohibition against unfair discrimination is designed to protect a class against the risk that the proponent will create other classes of the same legal rank and then provide more favorable treatment in the plan to those other classes. TABB; Charles J.; BRUBAKER, Ralph. Bankruptcy law: principles, policies, and practice. 3. ed. United States: Matthew Bender \& Company, Inc., 2011.

${ }^{2}$ However, discrimination is permissible if it is not unfair. The question of fairness has to be resolved by evaluating the need and motive for the discrimination. If it is justifiable - it has somes reasonable basis, it is not motivated by bad Faith, and it is necessary to the success of the reorganization - it will likely nor be unfair. BLUM, Brian A. Bankruptcy and debtor. Creditor: examples and explanations. 4. ed. United States: Aspen Publishers, 2006

${ }^{3}$ The fair and equitable test imports the absolute priority rule into the Code with respect to a dissenting class. The absolute priority rule requires honoring under the plan the nonbankruptcy priority ranking of various classes against the debtor and the debtor's assets. TABB; Charles J.; BRUBAKER, Ralph. Bankruptcy law: principles, policies, and practice. 3. ed. United States: Matthew Bender \& Company, Inc., 2011.

${ }^{4}$ Moreover, as a prerequisite to confirmation, the debtor must show that the Plan is economically feasible and is not likely to be followed by liquidation or need for further reorganization. MILLER, Frederick H.; HARRELL, Alvin C. The ABCs of the UCC. Relater insolvency law. United States: American Bar Association. 2002.
} 
A doutrina divide-se quanto ao tema. Isto porque muitos se referem à regra do $§ 10$ do art. 58 da LFRE usando a denominação cram down brasileiro, reforçando a recepção do instituto na legislação brasileira; enquanto outros criticam os requisitos necessários para sua aplicação, pois o modelo brasileiro assemelha-se ao norte-americano apenas no objetivo de homologar o plano de recuperação não aprovado totalmente pelos credores, possuindo requisitos diferentes e não dando margem subjetiva à análise do juiz.

Neste sentido, Simionato (apud OLIVEIRA; SCHLAUCHER, 2016) alega que o instrumento previsto no art. 58, §1으 da Lei n. $11.101 / 2005$ não se assemelha ao cram down americano pelo fato de não haver discricionariedade ao juiz na análise do plano de recuperação. Afirma, por fim, que "[...] não há cram down na lei 11.101/05, em hipótese alguma".

Apesar das críticas doutrinárias, há na jurisprudência vários casos de aplicação do cram down, em especial nos casos em que se verifica voto contrário dos credores das classes que possuam um ou poucos credores com alta porcentagem de crédito, ou seja, nos casos em que pode haver abuso de voto.

Sendo assim, havendo abusividade e, consequentemente, a impossibilidade de preenchimento do inciso III do artigo 58, a solução não é mais a imediata convolação da recuperação em falência prevista no art. 73, III da LFRE. A jurisprudência tem decidido essa questão em consonância com o interesse coletivo e os princípios da preservação e função social da empresa.

A exemplo tem-se a decisão proferida nos autos do Agravo de Instrumento n. 2017379 32.2014.8.26.0000, pelo Desembargador Ênio Santarelli Zuliani da 1a Câmara Reservada de Direito Empresarial do TJSP, recurso interposto pelo Banco do Brasil em face da decisão de concessão da recuperação judicial fundamentada no abuso de voto do banco que é credor único da classe com garantia real, possuindo, ainda, parte de seus créditos na classe quirografária.

No caso em questão, o juízo a quo decidiu pela concessão da recuperação, argumentando que, ao decidir de modo contrário, estaria permitindo que o banco, sozinho, decidisse pela aprovação ou não do plano recuperacional. Desta forma, o juízo ad quem manteve a decisão que utilizou o cram down, por entender que o princípio da preservação da empresa deve prevalecer, tendo em vista o interesse da totalidade dos credores.

Por outro lado, note-se que, em decisão sobre o abuso de voto, o Desembargador da 2a Câmara Reservada de Direito Empresarial do Tribunal de Justiça de São Paulo, ao julgar o agravo de instrumento interposto pelo Banco do Brasil, decidiu pela descaracterização do abuso de voto.

Neste caso, a empresa devedora apresentou plano de recuperação com previsão de pagamento à classe de credores a que pertence o agravante (classe quirografária) a partir de valores condicionados ao faturamento futuro da empresa, sendo impossível vislumbrar os valores a serem pagos aos credores, o que caracteriza a iliquidez da proposta.

Desta forma, verificou-se a justa oposição do agravante, tendo em vista que o plano não atendeu ao princípio da legalidade por não apresentar liquidez.

Pelo exposto, percebe-se que a aplicação do cram down pelos juízes singulares e a sua confirmação pelos tribunais brasileiros é rotineira, não seguindo rigorosamente seus parâmetros legais, mas amparado pelos princípios que regem o direito falimentar brasileiro.

\section{DO PODER DO JUIZ NA APLICAÇÃO DO INSTITUTO}

Uma questão acerca da atuação do juiz no cram down envolve a expressão "poderá" utilizada no $\S 2$ - do art. 58, da LRE, que deve ser compreendida não como uma faculdade do juiz para conceder a recuperação com base no cram down, mas sim um poder-dever.

Em relação ao poder do magistrado na aplicação do instituto, discute-se a possibilidade de o juiz analisar a viabilidade econômica do plano de recuperação judicial, sendo que a maior parte da doutrina concorda que o juiz não pode realizar tal exame. 
Isto porque são os credores que fazem essa avaliação, devendo o magistrado se limitar ao controle da legalidade do plano, como consta nos Enunciados da I Jornada de Direito Comercial de números 44 e 46, apenas analisando a presença dos requisitos do art. 45 ou do art. 58, §1ㅇe e eventual aplicação do cram down, bem como adequando os procedimentos às normas de nossa Constituição Federal.

Segundo Mamede (2016, p. 172), o controle de legalidade serve para apurar eventual abuso de direito ou tratamento diferenciado dos credores. Aduz, também, que "se a ilegalidade estiver restrita a determinada(s) cláusula(s) do plano, bastará a anulação destas, mantendo a concessão da recuperação judicial e, assim, a validade e efetividade das demais deliberações", o que, como já visto, caracteriza o cram down.

Desta forma, percebe-se a atuação delimitada do juiz, que não possui muitos instrumentos para analisar de modo amplo a viabilidade da empresa.

\section{CONCLUSÃO}

No atual cenário empresarial, as empresas, diante das crises enfrentadas, buscam soluções para seu soerguimento, desde que minimamente viáveis. Assim, verificada sua capacidade de reorganização, podem requerer sua recuperação perante o Poder Judiciário.

A Lei n.o 11.101/2005 introduziu a figura da recuperação de empresas no Brasil, trazendo dentro de sua modalidade jurídica um instituto próprio do direito norte-americano denominado cram down.

A ideia do instituto é a de garantir a preservação da empresa por meio de uma decisão isolada do juiz quando a quantidade de votos da Assembleia Geral dos Credores necessária para aprovação do plano de recuperação judicial apresentado pela sociedade empresária devedora não é atingida, mas, ainda assim, há apoio substancial dos credores.

Deste modo, prezando pelos princípios da preservação e da função social da empresa, a aprovação através do cram down, se mostra eficiente no combate ao abuso de uma minoria de credores de uma só classe.

Apesar de receber críticas da doutrina, o cram down é instituto reconhecido no direito brasileiro, contudo não é exatamente igual ao dos Estados Unidos, possuindo características próprias definidas pela jurisprudência.

O magistrado, responsável por realizar o controle de legalidade do processo de recuperação de uma empresa, limita-se à análise objetiva dos requisitos impostos pelos parágrafos 10 e 20 do artigo 58 da referida lei. Contudo, possui certa discricionariedade ao decidir pela concessão da recuperação nos casos de abuso de voto dos credores únicos de uma só classe.

A limitação do juiz brasileiro se dá, ainda, por não possuir o suporte técnico acerca de matérias econômicas em comparação com o direito norte-americano que tem a figura da Securities and Exchance Comission para auxiliar o juiz em sua análise do plano de reorganização.

Desta forma, o juiz não possui plena competência para verificar questões econômicas, ficando a cargo dos credores decidirem se o plano possui capacidade de atender às expetativas apresentadas.

Desta forma, conclui-se que é necessária uma revisão dos requisitos exigidos para conceder a recuperação judicial, assemelhando-os aos constantes no Bankruptcy Code dos Estados Unidos, inclusive na questão do auxílio de um órgão especializado ao juiz.

Tais providências dariam mais liberdade para o juiz melhor analisar o plano de recuperação judicial e homologa-lo sem a anuência de todos os credores, garantindo atendimento a todos os princípios aplicáveis ao direito recuperacional. 


\section{REFERÊNCIAS}

BLUM, B. A. Bankruptcy and debtor. Creditor: examples and explanations. 4. ed. United States: Aspen Publishers, 2006. Disponível em: <https://books.google.com.br/books?id=IDKVG9ndleAC\&pg=PA513\&dq=cram+down+unfair+discri mination\&hl=pt-

BR\&sa=X\&ved=0ahUKEwjmh8invu_aAhVJhpAKHS2cBPkQ6AEIKDAA\#v=onepage\& $q \& f=f a l s e>$. Acesso em: 04 mai. 2018.

BRASIL. Lei de Falência e Recuperação de Empresas. Lei n.o 11.101, 9 de fevereiro de 2005. Regula a recuperação judicial, a extrajudicial e a falência do empresário e da sociedade empresária. Disponível em: < http://www.planalto.gov.br/ccivil_03/_ato2004-2006/2005/lei/l11101.htm>. Acesso em 12 abr. 2018.

BRASIL. Tribunal de Justiça do Estado de São Paulo. 1a Câmara Reservada de Direito Empresarial. AGRAVO DE INSTRUMENTO. RECUPERAÇÃO JUDICIAL. Pedido de desconstituição do plano de recuperação homologado. Plano de recuperação homologado, a despeito de possuir ilegalidades. Homologação com base na teoria do Direito Anglo Saxônico denominada cram down. Adequação ao caso. Impossibilidade de cumprimento do requisito do art. 58, §1으, III, da LRE, já que a classe que rejeitou o plano é composta de um único credor. Deságio está de acordo com a realidade econômica atual da empresa em recuperação. Créditos quirografários que serão pagos de acordo com o que foi decidido em AGC, já que o pagamento dar-se-á em tempo exíguo. O mesmo também será feito relativamente aos créditos reais, na medida em que o plano foi efetivamente aprovado pelo Cram Down e as matérias referentes aos juros e correção monetária materializam direito disponível, tal qual o prazo de carência. Inexigibilidade de apresentação das certidões negativas de débitos tributários, nos termos dos julgados das Câmaras Reservadas de Direito Empresarial não provimento. Agravo de Instrumento n.o 2017379-32.2014.8.26.0000. Agravante: Banco do Brasil S.A. Agravado: Gutierrez Empreendimentos e Participações Ltda (Em Recuperação Judicial). Relator: Enio Zuliani. São Paulo, 11 de setembro de 2014. Disponível em: $<$ https://esaj.tjsp.jus.br/cjsg/getArquivo.do?conversationld=\&cdAcordao=7865689\&cdForo=0\&uu idCaptcha=sajcaptcha cfdc461bede741f4ba459da49f0737e2\&vlCaptcha=kce\&novoVICaptcha=>.

Acesso em 08 mai. 2018.

COSTA, D. C. A viabilidade da atividade empresarial como pressuposta da sua recuperação. Carta Forense. São Paulo, 01 fev. 2013. Disponível em: <http://www.cartaforense.com.br/conteud/artigos/a-viabilidade-da-atividade--empresarial-comopressuposta--da-sua-recuperacao-judicial/10374>. Acesso em: 21 nov. 2017.

ESTADOS UNIDOS. United States Congress. Bankruptcy Code, 1978. Disponível em: <https://www.usbankruptcycode.org/>. Acesso em 02 mai. 2018.

LIMA FILHO, G. A. A juridicidade e os parâmetros para aplicação do instituto norte-americano do cram down nas recuperações judiciais de emrpesas no Brasil. Revista Jus Navigandi. Teresina, 03 mai. 2017. Disponível em: <https://jus.com.br/artigos/56279>. Acesso em: 26 fev. 2018.

MAMEDE, G. Direito empresarial brasileiro: falência e recuperação de empresas, vol. 4. 8. ed. São Paulo: Atlas, 2016. Disponível em: <https://integrada.minhabiblioteca.com.br/\#/books/9788597007923/cfi/6/10!/4/22/2@0:0>. Acesso em 16 abr. 2018. 
MILLER, F. H.; HARRELL, A. C. The ABCs of the UCC. Relater insolvency law. United States: American Bar Association. $2002 . \quad$ Disponível em: <https://books.google.com.br/books?id=Bby6RFNZVYsC\&pg=PA13\&dq=cram+down\&hl=ptBR\&sa= $\mathrm{X} \&$ ved=0ahUKEwjMiq2hrO_aAhXCXpAKHZIVC2sQ6AEIMTAB\#v=onepage\& $\mathrm{q}=$ feasible $\& \mathrm{f}=$ false $>$. Acesso em: 04 mai. 2018.

OLIVEIRA, D. L. M. de; SCHLAUCHER, Débora Guedes. Reflexões acerca do instituto do cram down na Lei 11.101/2005. Âmbito Jurídico, Rio Grande, XIX, n. 155, 2016. Disponível em: <http://www.ambitojuridico.com.br/site/index.php?n_link=revista_artigos_leitura\&artigo_id=183 00\&revista_caderno=8>. Acesso em: 03 mai. 2018.

TABB; C. J.; BRUBAKER, R. Bankruptcy law: principles, policies, and practice. 3. ed. United States: Matthew Bender \& Company, Inc., 2011. Disponível em: <https://books.google.com.br/books?id=GA5rpbh7y58C\&pg=RA1-PT757\&lpg=RA1PT757\&dq=1129(b)(1)+cram+down\&source=bl\&ots=iv4Go1BS8D\&sig=U4Hn2vOTTGEFhEhNu1jdF $H 25 Z J Y \& h l=p t-B R \& s a=X \# v=$ onepage $\& q=1129(b)(1) \% 20$ cram\%20down\&f=false $>$. Acesso em 04 mai. 2018. 